\title{
PET/CT Imaging of Chemokine Receptors in Inflammatory Atherosclerosis Using Targeted Nanoparticles
}

\author{
Hannah P. Luehmann ${ }^{1}$, Lisa Detering ${ }^{1}$, Brett P. Fors ${ }^{2}$, Eric D. Pressly ${ }^{2}$, Pamela K. Woodard ${ }^{1}$, Gwendalyn J. Randolph ${ }^{3}$, \\ Robert J. Gropler ${ }^{1}$, Craig J. Hawker ${ }^{2}$, and Yongjian Liu ${ }^{1}$ \\ ${ }^{I}$ Department of Radiology, Washington University, St. Louis, Missouri; ${ }^{2}$ Department of Materials, Chemistry and Biochemistry, \\ University of California, Santa Barbara, California; and ${ }^{3}$ Department of Pathology and Immunology, Washington University, \\ St Louis, Missouri
}

\begin{abstract}
Atherosclerosis is inherently an inflammatory process that is strongly affected by the chemokine-chemokine receptor axes regulating the trafficking of inflammatory cells at all stages of the disease. Of the chemokine receptor family, some specifically upregulated on macrophages play a critical role in plaque development and may have the potential to track plaque progression. However, the diagnostic potential of these chemokine receptors has not been fully realized. On the basis of our previous work using a broad-spectrum peptide antagonist imaging 8 chemokine receptors together, the purpose of this study was to develop a targeted nanoparticle for sensitive and specific detection of these chemokine receptors in both a mouse vascular injury model and a spontaneously developed mouse atherosclerosis model. Methods: The viral macrophage inflammatory protein-II (VMIP-II) was conjugated to a biocompatible poly(methyl methacrylate)-core/polyethylene glycol-shell amphiphilic comblike nanoparticle through controlled conjugation and polymerization before radiolabeling with ${ }^{64} \mathrm{Cu}$ for PET imaging in an apolipoprotein $\mathrm{E}$-deficient $\left(\mathrm{ApoE}^{-/-}\right)$mouse vascular injury model and a spontaneous $\mathrm{ApoE}^{-/-}$mouse atherosclerosis model. Histology, immunohistochemistry, and real-time reverse transcription polymerase chain reaction were performed to assess the plaque progression and upregulation of chemokine receptors. Results: The chemokine receptortargeted ${ }^{64} \mathrm{Cu}$-VMIP-II-comb showed extended blood retention and improved biodistribution. PET imaging showed specific tracer accumulation at plaques in $\mathrm{ApoE}^{-/-}$mice, confirmed by competitive receptor blocking studies and assessment in wild-type mice. Histopathologic characterization showed the progression of plaque including size and macrophage population, corresponding to the elevated concentration of chemokine receptors and more importantly increased PET signals. Conclusion: This work provides a useful nanoplatform for sensitive and specific detection of chemokine receptors to assess plaque progression in mouse atherosclerosis models.
\end{abstract}

Key Words: PET/CT; viral macrophage inflammatory protein-II; chemokine receptor; nanoparticle; atherosclerosis

J Nucl Med 2016; 57:1124-1129

DOI: 10.2967/jnumed.115.166751

Received Sep. 13, 2015; revision accepted Dec. 7, 2015.

For correspondence or reprints contact: Yongjian Liu, Department of Radiology, Washington University, Campus Box 8225, 510 S. Kingshighway Blvd., St. Louis, MO 63110.

E-mail: liuyo@mir.wustl.edu

Published online Jan. 21, 2016.

COPYRIGHT (C 2016 by the Society of Nuclear Medicine and Molecular Imaging, Inc.
A therosclerosis is essentially an inflammatory disease, in which inflammation has critical roles in the initiation, progression, and eventual clinical event. Of many studies identifying biomarkers in atherosclerosis, most have centered on addressing leukocyte influx in plaque initiation. This establishes a prime role for selectin family members (i.e., E-selectin) in the capture, tethering, and rolling of circulating monocytes onto the inflamed endothelium and for endothelial adhesion molecules (e.g., ICAM-1, VCAM-1) that mediate leukocyte arrest by interacting with integrins on activated monocytes (1-3). However, leukocyte influx in advanced plaque has shown large variability during the progression of atherosclerosis, which significantly affects the expression of associated biomarkers and requires further studies to investigate the correlation of their expression with the maturation of disease (4-6).

Chemokines are a group of small heparin-binding proteins significantly involved in plaque initiation, progression, destabilization, and rupture due to their critical roles in directing the movement of circulating leukocytes to sites of inflammation or injury through corresponding chemokine receptors $(4,7,8)$. During this longitudinal process, the altered plaque composition is translated in a changed panel of secretory mediators and chemokine receptors (9-13). Because of the promiscuous binding nature of chemokines to their receptors, there are approximately 10 chemokine receptors identified at the atherosclerotic lesions including CCR1, CCR2, CCR3, CCR4, CCR5, CCR8, CXCR2, CXCR3, CXCR4, and CX3CR1. These receptors are actively expressed in inflammatory cells such as macrophages/ monocytes and play fundamental roles from the initiation to progression of atherosclerotic plaque (14-17). Preclinical studies showed that the progression of atherosclerotic lesions correlates well with an increase of chemokine receptor concentration expressed within aortas, which makes chemokine receptors not only interesting targets to monitor atherosclerosis progression $(18,19)$ but also therapeutic biomarkers for specific intervention through nanoplatforms $(20,21)$. However, the targeting efficiency and specificity of these nanoprobes needs significant improvement.

Previously, we developed a vMIP-II peptide-based PET tracer $\left({ }^{64} \mathrm{Cu}\right.$-DOTA-vMIP-II) for specific imaging of the upregulation of a group of chemokine receptors expressed at the injured femoral artery of apolipoprotein E-deficient ( $\mathrm{ApoE}^{-1-}$ ) mice (22). However, the detection sensitivity and specificity need further improvement because of the fast renal clearance of the tracer. Herein, we prepared a comblike nanoparticle conjugated with multiple copies of vMIP-II peptide and radiolabeled with ${ }^{64} \mathrm{Cu}\left({ }^{64} \mathrm{Cu}\right.$-vMIP-II-comb) to enhance the systemic circulation and improve the detection sensitivity and 
specificity in the $\mathrm{ApoE}^{-/-}$mouse vascular injury model (23-25). Furthermore, this ${ }^{64} \mathrm{Cu}$-vMIP-II-comb was used to measure the spatial and temporal expression patterns of these receptors upregulated at the aortic arch of $\mathrm{ApoE}^{-/-}$mice along the progression of plaque with PET/CT. The quantitative tracer uptake was correlated to the reverse transcription polymerase chain reaction (RT-PCR) measurement of chemokine receptor expression, histology, macrophage population, and plaque size.

\section{MATERIALS AND METHODS}

Materials were purchased from Sigma-Aldrich and used without further purification unless otherwise stated. The ${ }^{64} \mathrm{Cu}$ (half-life $=12.7 \mathrm{~h}$, $\beta^{+}=17 \%, \beta^{-}=40 \%$ ) was produced at Washington University (26). Functionalized poly(ethylene glycol) derivatives were obtained from Intezyne Technologies. Tris-t-butylester-DOTA, 1,4,7,10tetraazacyclododecane, and DOTA- $N$-hydroxysuccinimide ester were purchased from Macrocyclics. Viral macrophage inflammatory protein-II (vMIP-II) was customized by CPC Scientific. DOTA methacrylate, dithioester radical addition fragmentation transfer agent, control comb, and 4-pentynoic n-hydroxy succinimide ester were also prepared (26-28). Centricon tubes were from Millipore. Zeba desalting spin columns were obtained from Pierce. The reversed-phase highperformance liquid chromatography system was equipped with a UV/VIS and a C-18 analytic column $(5 \mathrm{~mm}, 4.6 \times 220 \mathrm{~mm}$; Perkin Elmer). Polymeric materials were characterized by ${ }^{1} \mathrm{H}$ and ${ }^{13} \mathrm{C}$ nuclear MR spectroscopy using either a Varian $500-\mathrm{MHz}$ or Varian $600-\mathrm{MHz}$ instrument with the residual solvent signal as an internal reference. Gel permeation chromatography was performed in $\mathrm{N}, \mathrm{N}$-dimethylformamide on a Waters system equipped with $45-\mu \mathrm{m}$ Waters columns $(300 \times 7.7 \mathrm{~mm})$ connected in series with increasing pore size $\left(10^{2}, 10^{3}, 10^{4}\right.$, and $\left.10^{6} \AA\right)$ and Waters 410 differential refractometer index and 996 photodiode array detectors. The molecular weights of the polymers were calculated relative to linear polystyrene or poly(ethylene oxide) standards. Infrared spectra were pling accessory.

\section{Polymer Synthesis, Deprotection, Assembly, and vMIP-II Conjugation}

The synthesis of poly(ethylene glycol) $\alpha$-bromide methacrylate and DOTA- $\alpha$-bromide-comb followed that described in a previous report and is detailed in the supplemental data (supplemental materials are detector (Dionex), a radioactivity detector (B-FC-3200; BioScan Inc.), recorded on a Perkin Elmer Spectrum 100 with a Universal ATR sam-

available at http://jnm.snmjournals.org). The polymer $(15 \mathrm{mg})$ was deprotected and assembled into particles (Fig. 1) (26). To a $0.5-\mathrm{mL}$ solution of the deprotected and assembled nanoparticles (1 weight percent [wt \%]), $250 \mu \mathrm{L}$ of a $0.4 \mathrm{wt} \%$ solution of vMIP-II in an $\mathrm{NH}_{4} \mathrm{OAc}$ buffer were added and reacted overnight. The solution was then diluted with water, transferred to a centrifugal filtration tube with a 50-kDa molecular weight cutoff, and extensively washed with water. The final solution was concentrated to $1 \mathrm{wt} \%$ nanoparticles in water using centrifugal filtration. The averaged hydrodynamic size of the vMIP-II-comb characterized by dynamic light scattering was $15.8 \pm$ $2.0 \mathrm{~nm}$ with neutral surface charge ( $\zeta$ potential, $5.4 \pm 1.1 \mathrm{mV}$, Supplemental Fig. 1). There were approximately 4 vMIP-II peptides and 70 DOTA per nanoparticle. The nontargeted comb $(\zeta$ potential, $-32 \pm$ $3 \mathrm{mV}, 25 \pm 2 \mathrm{~nm}$ ) was also prepared (26).

\section{ApoE $^{-/-}$Mouse Vascular Injury and Spontaneous Atherosclerosis Models}

All animal studies were performed in compliance with guidelines set forth by the National Institutes of Health Office of Laboratory Animal Welfare and approved by the Washington University Animal Studies Committee. The mouse vascular injury model was induced in male apolipoprotein E knock-out (ApoE $\left.{ }^{-1-}\right)$ mice $(n=16,6$-wk-old; Taconic Inc.) through wire injury on the right femoral artery $(22,23,29,30)$. The left femoral artery was surgically prepared by incision and closure without guide wire endothelial injury to serve as the sham site. Wild-type (WT) male C57BL/6 mice $(n=5)$ on normal chow that underwent the injury procedure were used as control animals. For the spontaneous atherosclerosis mouse model, male $\mathrm{ApoE}^{-1-}$ 6-wk-old mice were fed a high-cholesterol diet (HCD) (Harlan Teklad, $42 \%$ fat) for $37 \mathrm{wk}$. Age-matched WT male C57BL/6 mice on normal chow were used as controls. Each mouse was anesthetized with a standard inhaled-anesthetic protocol (1.5\%-2\% isoflurane) by induction in a chamber, and maintenance anesthesia was administered via a nose cone.

\section{Biodistribution Studies}

The specific activities of ${ }^{64} \mathrm{Cu}-\mathrm{vMIP}-\mathrm{II}-\mathrm{comb}$ and ${ }^{64} \mathrm{Cu}$-comb were 3.2 and $3.7 \mathrm{MBq} / \mathrm{nmol}$, respectively (25). Male WT C57BL/6 mice weighing $20-25 \mathrm{~g}$ ( $n=4 /$ group) were anesthetized with inhaled isoflurane, and approximately $370 \mathrm{kBq}$ of ${ }^{64} \mathrm{Cu}$-vMIP-II-comb $(\sim 0.12 \mathrm{nmol})$ in $100 \mu \mathrm{L}$ of saline were injected via the tail vein. The mice were reanesthetized before they were euthanized by cervical dislocation at each time point $(1,4,24$, and $48 \mathrm{~h})$ after injection. Organs of interest were collected, weighed, and counted in a well $\gamma$-counter (Beckman $8000)$ to calculate the percentage injected dose per gram of tissue (\% ID/g) (31).

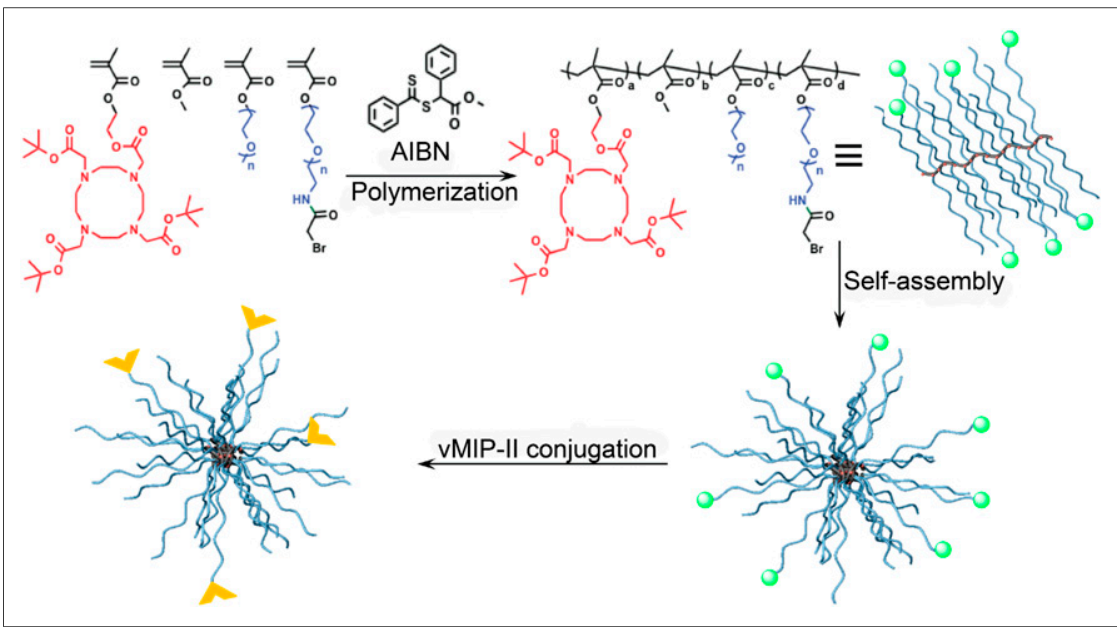

FIGURE 1. Synthesis of VMIP-II-comb (a-bromide, VMIP-II).

\section{Small-Animal PET/CT Imaging}

Two and 4 wk after the wire injury of the $\mathrm{ApoE}^{-1-}$ mice, PET/CT was performed to determine the uptake at injured lesions after the injection of $3.7 \mathrm{MBq}$ of ${ }^{64} \mathrm{Cu}$-vMIP-IIcomb or ${ }^{64} \mathrm{Cu}$-comb in $100 \mu \mathrm{L}$ of saline via the tail vein. PET/CT images were collected at $24 \mathrm{~h}$ after injection based on the biodistribution and previous report (23). The $\mathrm{ApoE}^{-1-}$ mice with spontaneous atherosclerosis lesion and age-matched WT C57BL/6 mice were scanned at 20 and 37 wk on HCD with both ${ }^{64} \mathrm{Cu}$-vMIP-II-comb and ${ }^{64} \mathrm{Cu}$-comb (at $24 \mathrm{~h}$ after injection) with an Inveon PET/CT scanner (Siemens) (CT: $8 \mathrm{~min}, 80 \mathrm{kVp}, 500 \mu \mathrm{A}$, $250 \mathrm{~ms}, 200 \mu \mathrm{m}$ pixel size; PET: 1 frame, 


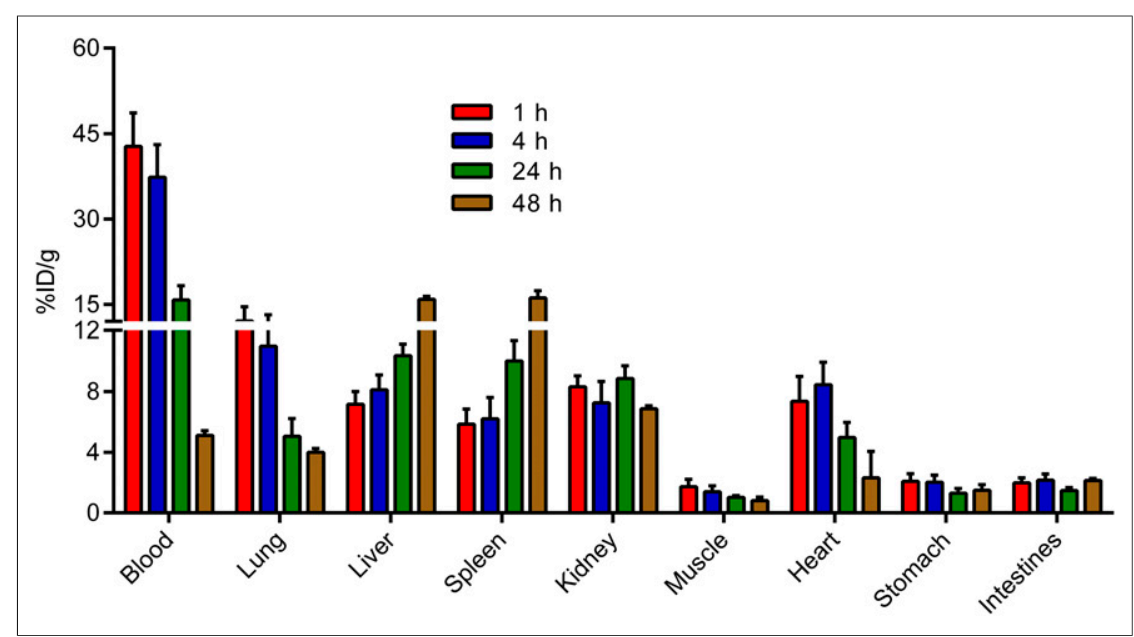

FIGURE 2. Biodistribution of ${ }^{64} \mathrm{Cu}-\mathrm{vMIP}-\mathrm{II}-\mathrm{comb}$ in WT C57BL/6 mice ( $n=4 /$ group).

\section{Statistical Analysis}

Group variation is described as mean $\pm \mathrm{SD}$ and compared using 1-way ANOVA with a Bonferroni adjustment. Individual group differences were determined by a 2-tailed MannWhitney test. The significance level in all tests was a $P$ value of 0.05 or less.

\section{RESULTS}

\section{Biodistribution of ${ }^{64} \mathrm{Cu}$-vMIP-II-Comb}

Biodistribution of ${ }^{64} \mathrm{Cu}-\mathrm{comb}$ was previously reported showing moderate blood retention but high mononuclear phagocyte system (liver and spleen) accumulation (25) whereas the ${ }^{64} \mathrm{Cu}$-DOTA-vMIP-II peptide tracer alone showed rapid renal clearance (22). At $1 \mathrm{~h}$ after injection, the blood retention of ${ }^{64} \mathrm{Cu}-\mathrm{vMIP}-\mathrm{II}-\mathrm{comb}(42.7 \pm$ $5.9 \% \mathrm{ID} / \mathrm{g})$ was significantly $(P<0.001$,

60-min static scan). PET data were analyzed using the manufacturer's software (ASI Pro or IRW). The tracer uptake at the region of interest was calculated as \% ID/g from the maximum a posteriori reconstructed images. After the last scan, the animals were euthanized by cervical dislocation, and the femoral vessels and aortic arches were either perfusion-fixed in situ with freshly prepared $4 \%$ paraformaldehyde in $1 \times$ phosphate-buffered saline for histopathology and immunohistochemistry or fast-frozen for RT-PCR analysis. Competitive receptor blocking studies were performed in both models for ${ }^{64} \mathrm{Cu}$-vMIP-IIcomb by coinjection of unlabeled vMIP-II-comb in 100-fold excess $(n=6)$ followed by PET scans at $24 \mathrm{~h}$ after injection.

\section{Histologic Characterization of Atherosclerotic Plaques and RT-PCR Assay of Chemokine Receptors}

Serial sections of mouse aortic arch of $5 \mu \mathrm{m}$ in thickness were cut from paraformaldehyde-fixed ( $24 \mathrm{~h}$ ), paraffin-embedded specimens for hematoxylin and eosin and macrophage (F4/80 mAb, AbD Serotec MCA497BB) staining. Quantification of plaque area and macrophage was calculated with ImageJ software (National Institutes of Health) following a published protocol (12). Tissue RNA was isolated using TRIzol (Invitrogen) per the manufacturer's instruction. RNA isolated from injured and sham femoral arteries was used for real-time RT-PCR. Reverse transcription reactions used $1 \mu \mathrm{g}$ of total RNA, random hexamer priming, and Superscript II reverse transcriptase (Invitrogen). Expression of chemokine receptors and glyceraldehyde 3-phosphate dehydrogenase (GAPDH) were determined using Taqman assays (Invitrogen) and an EcoTM Real-Time PCR System (Illumina) in duplicate in 48 -well plates. PCR cycling conditions were as follows: $50^{\circ} \mathrm{C}$ for $2 \mathrm{~min}, 95^{\circ} \mathrm{C}$ for $21 \mathrm{~s}$, and $60^{\circ} \mathrm{C}$ for $20 \mathrm{~s}$. GAPDH expression was used as a comparator using $\Delta \Delta \mathrm{Ct}$ calculations.

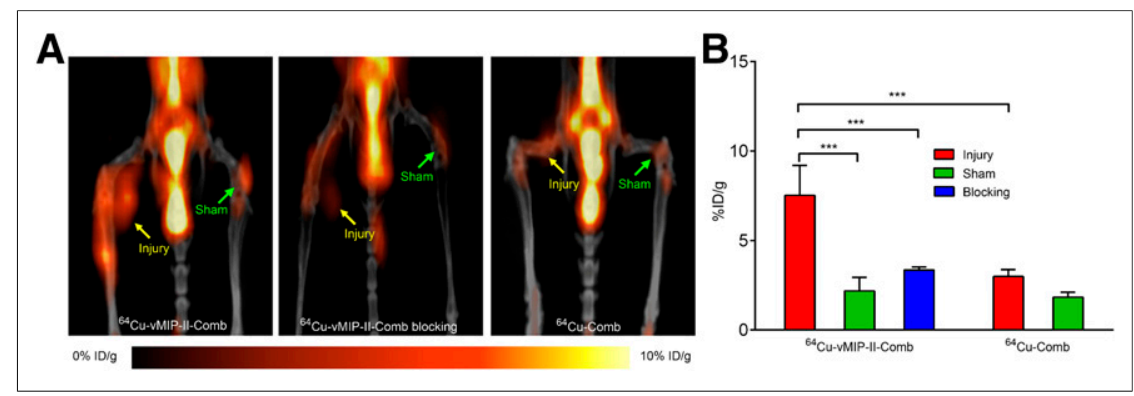

FIGURE 3. (A) Representative 24-h PET/CT images of ${ }^{64} \mathrm{Cu}$-vMIP-II-comb, blocking, and ${ }^{64} \mathrm{Cu}-$ comb in injured $\mathrm{ApoE}^{-/-}$mouse. (B) Quantitative uptake analysis. ${ }^{* \star *} P<0.001, n=6 /$ group. $n=4)$ higher than that of ${ }^{64} \mathrm{Cu}-\mathrm{comb}(25.4 \pm 3.0 \% \mathrm{ID} / \mathrm{g})$ (Fig. 2). The hepatic $(7.2 \pm 0.8 \% \mathrm{ID} / \mathrm{g})$ and splenic $(5.8 \pm 0.9 \% \mathrm{ID} / \mathrm{g})$ uptake were about 5 and 3 times less than those of ${ }^{64} \mathrm{Cu}$-comb, respectively. Consistent with previous reports using comb nanoparticles with neutral surface charge showing retentive blood circulation $(23,25)$, the blood-pool (sum of blood, lung, and heart) retention of ${ }^{64} \mathrm{Cu}$-vMIP-II-comb did not significantly decrease until $24 \mathrm{~h}$ after injection whereas its liver and spleen localizations $(\sim 10 \%$ ID/g for both) were still significantly $(P<0.001, n=4)$ lower than that of ${ }^{64} \mathrm{Cu}$-comb. At $48 \mathrm{~h}$ after injection, the blood retention of ${ }^{64} \mathrm{Cu}$-vMIP-II-comb decreased to $5.1 \pm 0.3 \% \mathrm{ID} / \mathrm{g}$, and the liver and spleen both gradually increased to approximately $16 \%$ ID/g. During the 48-h study, the renal and gastrointestinal tract showed constant clearance despite the variations in blood pool and mononuclear phagocyte system organs.

\section{PET/CT Imaging}

In the vascular injury model, PET/CT imaging with ${ }^{64} \mathrm{Cu}$-vMIP-IIcomb at $24 \mathrm{~h}$ after injection showed specific accumulation at the injured femoral artery and weak localization at the sham-operated site (Fig. 3A) at 2 wk after injury. Quantitative uptake analysis showed the uptake at the injury site was $7.52 \pm 1.67 \% \mathrm{ID} / \mathrm{g}$, significantly $(P<$ $0.001, n=6)$ higher than that of the sham site $(2.18 \pm 0.76 \% \mathrm{ID} / \mathrm{g})$. Consistent with a previous report about the stable uptake at the injured site with ${ }^{64} \mathrm{Cu}$-DOTA-vMIP-II peptide tracer alone between 2 and 4 wk after injury (22), the ${ }^{64} \mathrm{Cu}$-vMIP-II-comb also showed stable uptake at the injured artery $(6.92 \pm 1.06 \% \mathrm{ID} / \mathrm{g}$ at $4 \mathrm{wk}, n=6)$ during this period (Supplemental Fig. 2). Compared with the data obtained with ${ }^{64} \mathrm{Cu}$-DOTA-vMIP-II, the uptake of ${ }^{64} \mathrm{Cu}-\mathrm{vMIP}-\mathrm{II}-\mathrm{comb}$ at both time points was doubled $(P<0.005, n=6)$. The competitive PET blocking on the same mice at $3 \mathrm{wk}$ after injury with the coinjection of unlabeled vMIPII-comb resulted in substantial decrease at the injured site $(3.35 \pm 0.16 \% \mathrm{ID} / \mathrm{g}, n=6)$ to a level similar to those acquired at the sham site (Fig. 3B), which was significantly $(P<0.001)$ lower than the data obtained a week before.

Further, the nonspecific retention due to the size of the nanostructure at the injured site was also assessed with nontargeted ${ }^{64} \mathrm{Cu}$-comb. As shown in Figure 3A, little 


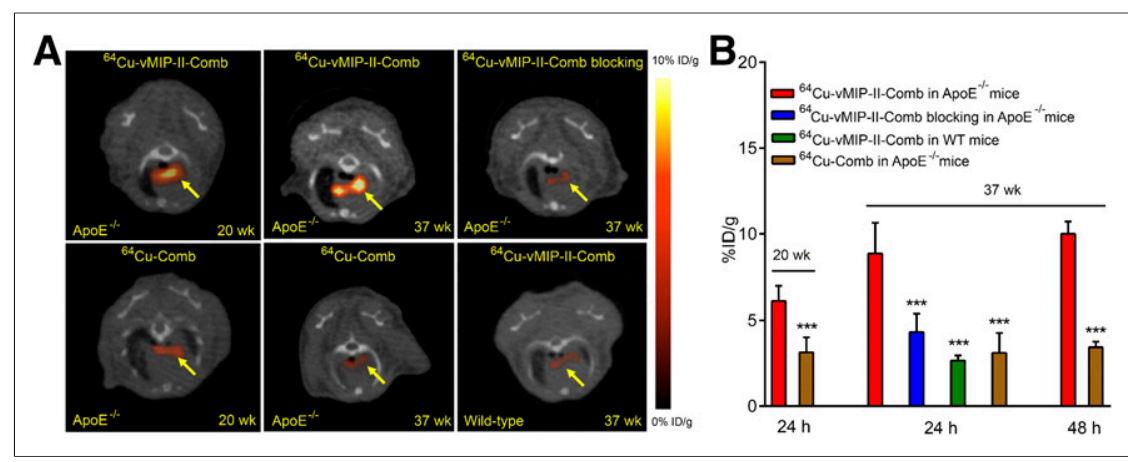

FIGURE 4. Representative 24-h PET/CT images (A) and uptake analysis (B) of ${ }^{64} \mathrm{Cu}-\mathrm{vMIP}-\mathrm{II}$ comb, blocking, and ${ }^{64} \mathrm{Cu}-\mathrm{comb}$ in $\mathrm{ApoE}^{-/-}$mouse spontaneous atherosclerosis model. ${ }^{\star \star \star} P<$ $0.001, n=6 /$ group.

uptake $(2.99 \pm 0.38 \% \mathrm{ID} / \mathrm{g})$ was observed at the injured artery, and the uptake analysis demonstrated significantly $(P<0.001$, $n=6$ ) lower accumulation at the injury lesion in contrast to the data obtained with targeted ${ }^{64} \mathrm{Cu}-\mathrm{vMIP}-\mathrm{II}-\mathrm{comb}$ (Fig. 2B), which was also confirmed by the results acquired at the 4-wk time point (Supplemental Fig. 2).

In the $\mathrm{ApoE}^{-1-}$ mice fed on $\mathrm{HCD}$ for $20 \mathrm{wk},{ }^{64} \mathrm{Cu}-\mathrm{vMIP}-\mathrm{II}-$ comb showed specific localization $(6.12 \pm 0.88 \% \mathrm{ID} / \mathrm{g}, n=6)$ at the aortic arch at $24 \mathrm{~h}$ after injection whereas the nontargeted ${ }^{64} \mathrm{Cu}$-comb showed significantly $(P<0.005, n=4)$ lower uptake at the lesion $(3.16 \pm 0.89 \% \mathrm{ID} / \mathrm{g})$. The target-to-background (T/B) ratio of ${ }^{64} \mathrm{Cu}-\mathrm{vMIP}-\mathrm{II}-\mathrm{comb}$ accumulation at the aortic arch to left ventricular cavity was $0.45 \pm 0.08(n=6)$, significantly $(P<$ $0.01, n=4-6 /$ group $)$ higher than that of ${ }^{64} \mathrm{Cu}$-comb $(0.23 \pm 0.11$, $n=4$ /group). With the progression of atherosclerosis, the plaque uptake of ${ }^{64} \mathrm{Cu}$-vMIP-II-comb at $24 \mathrm{~h}$ after injection significantly $(P<0.01, n=6)$ increased to $8.88 \pm 1.75 \% \mathrm{ID} / \mathrm{g}$ at $37 \mathrm{wk}$ on $\mathrm{HCD}$ whereas ${ }^{64} \mathrm{Cu}$-comb showed little variation $(3.10 \pm 1.16 \% \mathrm{ID} / \mathrm{g}$, $n=6$ ) (Figs. 4A and 4B). The T/B ratio of ${ }^{64} \mathrm{Cu}$-vMIP-II-comb also increased to $0.78 \pm 0.19(n=6)$ whereas the ratio of ${ }^{64} \mathrm{Cu}$-comb remained constant at $20 \mathrm{wk}(0.27 \pm 0.11, P<0.005, n=4-6 /$ group). At $48 \mathrm{~h}$ after injection, the plaque uptake of ${ }^{64} \mathrm{Cu}-\mathrm{vMIP}-\mathrm{II}-$ comb slightly increased to $10.0 \pm 0.72 \% \mathrm{ID} / \mathrm{g}$ (Fig. 4B), leading to a 2 -fold increase of $\mathrm{T} / \mathrm{B}$ ratio $(2.38 \pm 0.25, n=6 /$ group). The plaque 37 wk on HCD. uptake of ${ }^{64} \mathrm{Cu}$-comb hardly changed $(3.43 \pm$ $0.32 \% \mathrm{ID} / \mathrm{g}, n=4)$ although the T/B ratio $(0.82 \pm 0.65, n=4$ /group) increased because of its decreased blood retention. In the agematched WT mice, the retention of ${ }^{64} \mathrm{Cu}$ vMIP-II-comb at the aortic arch $(2.66 \pm$ $0.31 \% \mathrm{ID} / \mathrm{g})$ was also significantly $(P<$ $0.001, n=4)$ lower than the accumulation acquired in $\mathrm{ApoE}^{-1-}$ mice. More importantly, the competitive receptor blocking study significantly $(P<0.002, n=4)$ decreased the accumulation of ${ }^{64} \mathrm{Cu}-\mathrm{vMIP}$-IIcomb to a level $(4.31 \pm 1.07 \% \mathrm{ID} / \mathrm{g})$ similar to that obtained with ${ }^{64} \mathrm{Cu}$-comb (Fig. 4B). Additional autoradiography images of the 2 nanoprobes in the dissected aortic arches of $\mathrm{ApoE}^{-/-}$mice also confirmed the specific targeting of ${ }^{64} \mathrm{Cu}$-vMIP-II-comb (Supplemental Fig. 3). Consistent with previous studies comparing multivalent nanoparticles to monovalent peptide tracers alone $(23,25)$, the uptake of ${ }^{64} \mathrm{Cu}$-vMIP-II-comb at the aortic arch was 2 times higher than that acquired with ${ }^{64} \mathrm{Cu}$ DOTA-vMIP-II $(2.72 \pm 0.30 \% \mathrm{ID} / \mathrm{g}, \mathrm{T} / \mathrm{B}=0.76 \pm 0.07, n=4)$ at

\section{Histology, Immunohistochemistry, and RT-PCR}

The hematoxylin and eosin staining of right femoral arteries harvested from $\mathrm{ApoE}^{-1-}$ mice at 2 wk after injury demonstrated significant progression of plaque compared with the sham-operated left femoral artery (Supplemental Fig. 4) (23). In the ApoE ${ }^{-1-}$ spontaneous atherosclerosis mouse model, the formation of plaque was clearly observed at the aortic arch at $20 \mathrm{wk}$ on the HCD diet (Fig. 5A). The macrophage staining with F4/80 mAb showed positive cells on the surface of the plaque (Fig. 5B). Consistent with our previous report about the progression of atherosclerosis (12), the plaque at 37 wk after HCD showed increased lipid accumulation and became less cellular. The ImageJ analysis of advanced plaque showed a more than doubled (2.4-fold) size compared with that measured at 20 wk after HCD. F4/80 staining showed that most cells on the advanced plaque were positive and the signal was throughout the plaque. The quantification of macrophage area demonstrated 3.2-fold increase from the 20 -wk time point, which led to an increased macrophage-to-plaque ratio from $19.5 \%$ at $20 \mathrm{wk}$ to $26.7 \%$ at $37 \mathrm{wk}$. For the age-matched WT mice, histologic analysis of the aortic arch showed intact vasculature, and F4/80 staining showed little signal (Supplemental Fig. 5).

The expression of chemokine receptors on atherosclerotic plaque has been demonstrated in our previous studies $(22,23)$. The quantitative RT-PCR analysis of $\mathrm{ApoE}^{-1-}$ mice at 2 wk after injury showed much higher expression of CCR1, CCR2, CCR3, CCR4, CCR5, CCR8, CX3CR1, and CXCR4 in the injured femoral artery in comparison to the data obtained from sham-operated site (Fig. 6A). Compared with the WT mice, the elevated expression of 8 chemokine receptors on the plaque was determined in the $\mathrm{ApoE}^{-1-}$ spontaneous atherosclerosis mice at $20 \mathrm{wk}$ on $\mathrm{HCD}$

(Fig. 6B). In agreement with the increased size
FIGURE 5. Representative hematoxylin and eosin (H\&E) staining (40x) (A) and F4/80 staining (40x) (B) of plaques at 20 and $37 \mathrm{wk}$ on $\mathrm{HCD}$ in $\mathrm{ApoE}^{-/-}$mouse spontaneous atherosclerosis model. (C) Measurement of plaque area and F4/80 (brown)-positive area at 2 time points ${ }^{*} P<$ $0.05,{ }^{\star \star} P<0.005, n=3$ /group). $\mathrm{IHC}=$ immunohistochemistry. 
of plaque and macrophage-positive plaque area, the difference of chemokine receptor expression between the disease and WT mice was further increased at $37 \mathrm{wk}$ on HCD, especially for CCR2 (7.5-fold), CCR5 (5.4fold), CX3CR1 (5.3-fold), and CXCR4 (4.3-fold) (Fig. 6C).

\section{DISCUSSION}

We report here the results of PET/CT imaging of chemokine receptors upregulated in a vascular injury $\mathrm{ApoE}^{-1-}$ mouse model and a spontaneous atherosclerosis $\mathrm{ApoE}^{-/-}$mouse model with ${ }^{64} \mathrm{Cu}$-vMIPII-comb. The superiority of targeted imaging using multivalent nanoparticles was demonstrated by comparing the ${ }^{64} \mathrm{Cu}$-vMIP-II-comb with ${ }^{64} \mathrm{Cu}$-DOTA-vMIP-II peptide tracer alone and the nontargeted ${ }^{64} \mathrm{Cu}$-Comb. PET imaging showed an increased uptake of ${ }^{64} \mathrm{Cu}$-vMIPII-comb along the progression of plaque in the spontaneous atherosclerosis model, which correlated with the enlarged plaque size, increased macrophage population, and elevated chemokine receptor expression.

It is known that chemokine-chemokine receptor interactions play a key role in the pathogenesis of atherosclerosis by regulating leukocyte trafficking and the inflammatory processes to promote the progression of disease, which leads to the development of many chemokine receptor antagonists for clinical studies by targeting

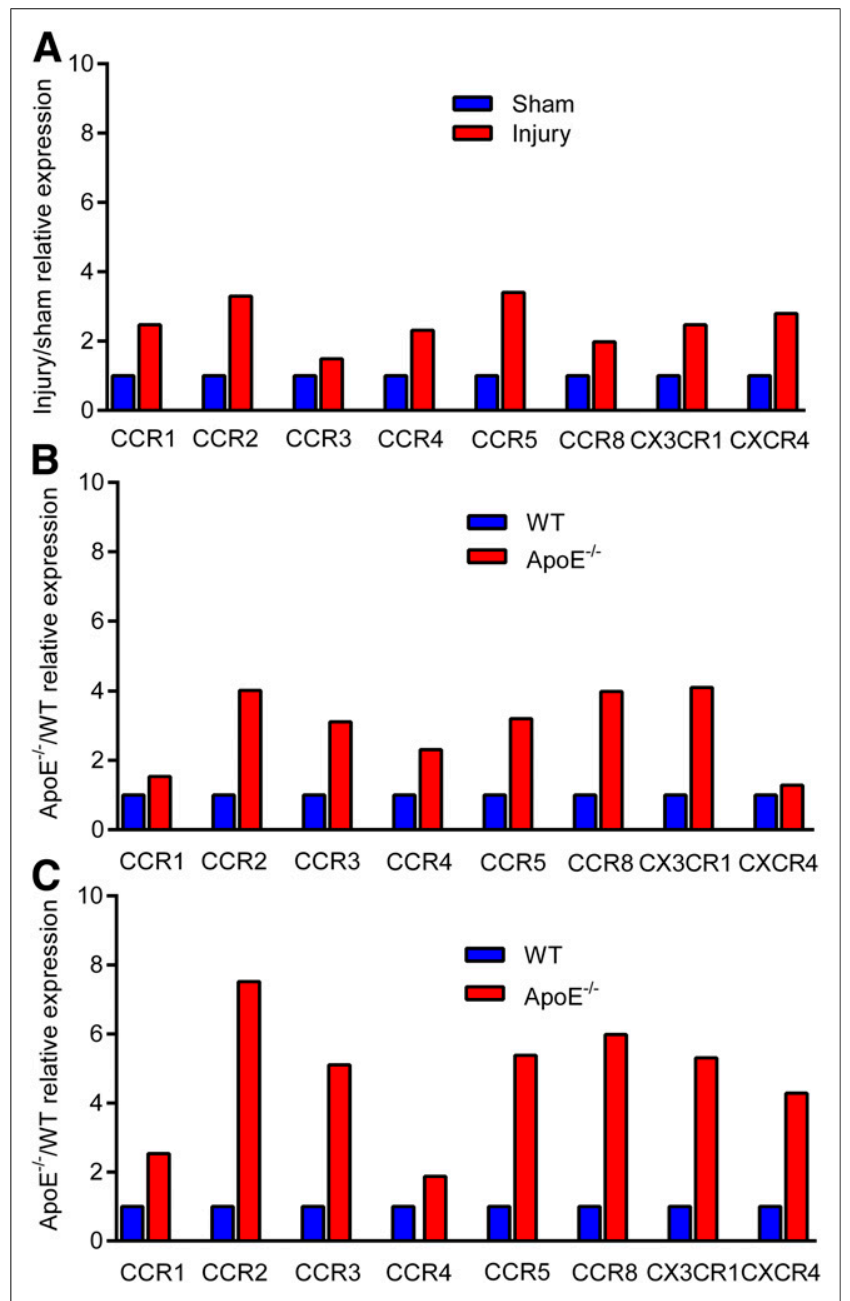

FIGURE 6. RT-PCR analysis of 8 chemokine receptors in injured and sham-operated femoral arteries (A) at 2 wk after injury in $\mathrm{ApoE}^{-/-}$mice. WT mice fed with normal chow and $\mathrm{ApoE}^{-/-}$mice fed with $\mathrm{HCD}$ at 20 (B) and 37 (C) wk ( $n=3-5 /$ group). specific chemokine receptors (32). However, most of these chemokine receptor antagonists have limited efficacy because of the redundancy of chemokine signaling pathways and dynamic and stage-specific expression of chemokine receptors, which makes a broad-spectrum chemokine receptor antagonist a rational and potentially more successful strategy by blocking a group of chemokine receptors at one time $(33,34)$. Previously, we have demonstrated the specific binding of the ${ }^{64} \mathrm{Cu}$-DOTA-vMIP-II peptide tracer alone to 8 chemokine receptors in the vascular injury model (22). Because of the fast renal clearance, the detection sensitivity and specificity need improvement to determine the plaque at an early stage when the chemokine receptor's expression is low. As shown in Figure 2, with the conjugation on the biocompatible poly(methyl methacrylate)core/polyethylene glycol-shell amphophilic nanoparticles, the blood retention of ${ }^{64} \mathrm{Cu}$-vMIP-II-comb was significantly extended, which led to doubled PET intensity at the injured site. Although the hepatic and splenic accumulation gradually increased during the 48-h study, they were significantly $(P<0.001, n=6$ ) lower than those obtained with the nontargeted ${ }^{64} \mathrm{Cu}$-comb, reasonably due to the effect of its neutral surface charge as reported previously (25). In addition, there was constant kidney accumulation, indicating renal clearance. The stomach and intestine uptake suggested later fecal excretion of the nanoparticles reasonably coming from the liver. Further, the targeting specificity was also demonstrated by the competitive PET blocking study and significantly lower uptake acquired with ${ }^{64} \mathrm{Cu}$-comb. Consistent with PET imaging, the RT-PCR analysis of the injured femoral artery showed elevated expression of all chemokine receptors compared with the sham-operated artery.

In the ApoE ${ }^{-1-}$ mouse spontaneous atherosclerosis model, the targeted ${ }^{64} \mathrm{Cu}$-vMIP-II-comb showed significantly higher accumulation at the aortic arch than that acquired with nontargeted ${ }^{64} \mathrm{Cu}$-comb and ${ }^{64} \mathrm{Cu}$-DOTA-vMIP-II peptide tracer alone, especially at the extended imaging time point of $48 \mathrm{~h}$ after injection, demonstrating the advantage of targeted, long circulating nanoparticles for atherosclerosis PET imaging. The competitive blocking study and the ex vivo autoradiography images confirmed the chemokine receptor-mediated uptake in the plaque, which was also corroborated by the low retention of ${ }^{64} \mathrm{Cu}$-vMIP-II-comb at the aortic arch of WT mice. In contrast to a previous report using nontargeted nanoparticle for plaque PET imaging (35), quantitative uptake analysis of targeted ${ }^{64} \mathrm{Cu}-$ vMIP-II-comb showed higher accumulation in the aorta and greater $\mathrm{T} / \mathrm{B}$ ratio. With the progression of disease, the plaque size at $37 \mathrm{wk}$ increased 1.4-fold compared with that measured at $20 \mathrm{wk}$, which was in agreement with the increased uptake $(45.1 \%)$ of ${ }^{64} \mathrm{Cu}-\mathrm{vMIP}-\mathrm{II}-$ comb, confirming our hypothesis of using a broad-spectrum chemokine receptor ligand to determine the plaque burden.

At all stages of plaque, macrophages are the central cells involved, though the complexity of the lesions grows in advanced plaque. It is thought that macrophages are major contributors to the inflammatory response through their secretion of proinflammatory mediators such as chemokines to arrest leukocytes to the plaque $(35,36)$. At $20 \mathrm{wk}$ on HCD, immunohistochemical analysis showed the upregulation of macrophages on the surface of the plaque. The RT-PCR analysis also demonstrated elevated expression of the 8 chemokine receptors in the plaque of $\mathrm{ApoE}^{-1-}$ mice compared with WT mice. With the progression of plaque, the histopathologic analysis showed not only the complication of plaque, including high lipid accumulation and calcification, but also the elevated expression of macrophages in contrast to the data acquired at $20 \mathrm{wk}$ on HCD, which was also confirmed by the enlarged plaque size and increased plaque area positive for macrophages. More importantly, the RT-PCR 
analysis of these chemokine receptors showed the amplified difference between the $\mathrm{ApoE}^{-1-}$ and WT mice during the atherosclerosis progression, which not only correlated with the progression of plaque properties but also was in agreement with the increased uptake of ${ }^{64} \mathrm{Cu}$-vMIP-IIcomb at the aortic arch. Currently, there are some PET tracers used in clinical research for atherosclerosis imaging such as ${ }^{18} \mathrm{~F}-\mathrm{FDG}$ or ${ }^{68} \mathrm{Ga}-$ DOTATATE (37). Most of them focus on the individual process such as glucose metabolism or a single target such as somatostatin receptors. Because of the complex and dynamic nature of the disease, these imaging agents are challenged to connect the plaque progression to the PET signal. However, this broad-spectrum chemokine receptortargeting nanoprobe may be valuable in assessing the plaque burden and activity due to the active expression and critical roles of these receptors for atherosclerosis progression and deliver useful information for both diagnosis and treatment in translational research given the success of a similar nanostructure for human plaque PET imaging (38).

\section{CONCLUSION}

In this study, we developed a broad-spectrum chemokine receptor antagonist vMIP-II-conjugated nanoparticle of ${ }^{64} \mathrm{Cu}$-vMIP-II-comb prepared with controlled physicochemical properties. The extended blood retention and improved targeting efficiency of ${ }^{64} \mathrm{Cu}-\mathrm{vMIP}-\mathrm{II}-$ comb afforded sensitive and specific detection of 8 chemokine receptors upregulated in a vascular injury mouse model and a spontaneously developed atherosclerosis mouse model. The increased accumulation of ${ }^{64} \mathrm{Cu}$-vMIP-II-comb in plaque during the progression of atherosclerosis was confirmed by RT-PCR analysis of chemokine receptors and in agreement with the histopathologic characterization of plaque including enlarged size and increased macrophage content, indicating the potential of ${ }^{64} \mathrm{Cu}-\mathrm{vMIP}-\mathrm{II}-\mathrm{comb}$ to determine plaque progression.

\section{DISCLOSURE}

The costs of publication of this article were defrayed in part by the payment of page charges. Therefore, and solely to indicate this fact, this article is hereby marked "advertisement" in accordance with 18 USC section 1734. This work was supported by the National Heart, Lung, and Blood Institute as a Program of Excellence in Nanotechnology (HHSN268201000046C) and R01 (1R01HL125655-01). No other potential conflict of interest relevant to this article was reported.

\section{REFERENCES}

1. Dong ZM, Brown AA, Wagner DD. Prominent role of P-selectin in the development of advanced atherosclerosis in ApoE-deficient mice. Circulation. 2000;101:2290-2295.

2. Nakashima Y, Raines EW, Plump AS, Breslow JL, Ross R. Upregulation of VCAM-1 and ICAM-1 at atherosclerosis-prone sites on the endothelium in the ApoE-deficient mouse. Arterioscler Thromb Vasc Biol. 1998;18:842-851.

3. Wildgruber M, Swirski FK, Zernecke A. Molecular imaging of inflammation in atherosclerosis. Theranostics. 2013;3:865-884.

4. Kraaijeveld AO, de Jager SC, van Berkel TJ, Biessen EA, Jukema JW. Chemokines and atherosclerotic plaque progression: towards therapeutic targeting? Curr Pharm Des. 2007;13:1039-1052.

5. Charo IF, Ransohoff RM. The many roles of chemokines and chemokine receptors in inflammation. N Engl J Med. 2006;354:610-621.

6. Libby P. Inflammation in atherosclerosis. Arterioscler Thromb Vasc Biol. 2012;32: 2045-2051.

7. Braunersreuther V, Mach F, Steffens S. The specific role of chemokines in atherosclerosis. Thromb Haemost. 2007;97:714-721.

8. John AE, Channon KM, Greaves DR. Chemokines, chemokine receptors and atherosclerosis. In: Schwiebert LM, ed. Chemokines, Chemokine Receptors, and Disease. Amsterdam, The Netherlands: Elsevier 2005:223-253.

9. Veillard NR, Steffens S, Burger F, Pelli G, Mach F. Differential expression patterns of proinflammatory and antiinflammatory mediators during atherogenesis in mice. Arterioscler Thromb Vasc Biol. 2004;24:2339-2344.
10. Veillard NR, Braunersreuther V, Arnaud C, et al. Simvastatin modulates chemokine and chemokine receptor expression by geranylgeranyl isoprenoid pathway in human endothelial cells and macrophages. Atherosclerosis. 2006;188:51-58.

11. Gautier EL, Ivanov S, Lesnik P, Randolph GJ. Local apoptosis mediates clearance of macrophages from resolving inflammation in mice. Blood. 2013;122:2714-2722.

12. Potteaux S, Gautier EL, Hutchison SB, et al. Suppressed monocyte recruitment drives macrophage removal from atherosclerotic plaques of Apoe-/- mice during disease regression. J Clin Invest. 2011;121:2025-2036.

13. Tacke F, Alvarez D, Kaplan TJ, et al. Monocyte subsets differentially employ CCR2, CCR5, and CX3CR1 to accumulate within atherosclerotic plaques. J Clin Invest. 2007;117:185-194.

14. Quinones MP, Martinez HG, Jimenez F, et al. CC chemokine receptor 5 influences late-stage atherosclerosis. Atherosclerosis. 2007;195:e92-e103.

15. Bursill CA, Channon KM, Greaves DR. The role of chemokines in atherosclerosis: recent evidence from experimental models and population genetics. Curr Opin Lipidol. 2004;15:145-149.

16. White GE, Iqbal AJ, Greaves DR. CC chemokine receptors and chronic inflammationtherapeutic opportunities and pharmacological challenges. Pharmacol Rev. 2013;65:47-89.

17. Zernecke A, Shagdarsuren E, Weber C. Chemokines in atherosclerosis: an update. Arterioscler Thromb Vasc Biol. 2008;28:1897-1908.

18. Zernecke A, Weber C. Chemokines in the vascular inflammatory response of atherosclerosis. Cardiovasc Res. 2010;86:192-201.

19. Jerath MR, Kwan M, Liu P, Patel DD. Chemokine receptors in atherosclerosis. In: Harrison JK, Lukacs NW, eds. The Chemokine Receptors. Totowa, New Jersey: Humana Press; 2007:199-233.

20. Bahal R, McNeer NA, Ly DH, Saltzman WM, Glazer PM. Nanoparticle for delivery of antisense gammaPNA oligomers targeting CCR5. Artif DNA PNA XNA. 2013;4:49-57.

21. Leuschner F, Dutta P, Gorbatov R, et al. Therapeutic siRNA silencing in inflammatory monocytes in mice. Nat Biotechnol. 2011;29:1005-1010.

22. Liu Y, Pierce R, Luehmann HP, Sharp TL, Welch MJ. PET imaging of chemokine receptors in vascular injury-accelerated atherosclerosis. J Nucl Med. 2013;54:1135-1141.

23. Luehmann HP, Pressly ED, Detering L, et al. PET/CT imaging of chemokine receptor CCR5 in vascular injury model using targeted nanoparticle. J Nucl Med. 2014;55:629-634.

24. Liu Y, Welch MJ. Nanoparticles labeled with positron emitting nuclides: advantages, methods, and applications. Bioconjug Chem. 2012;23:671-682.

25. Liu Y, Pressly ED, Abendschein DR, et al. Targeting angiogenesis using a C-type atrial natriuretic factor-conjugated nanoprobe and PET. J Nucl Med. 2011;52:1956-1963.

26. Pressly ED, Pierce RA, Connal LA, Hawker CJ, Liu Y. Nanoparticle PET/CT imaging of natriuretic peptide clearance receptor in prostate cancer. Bioconjug Chem. 2013;24:196-204.

27. Perrier S, Takolpuckdee P. Macromolecular design via reversible additionfragmentation chain transfer (RAFT)/xanthates (MADIX) polymerization. J Polym Sci A Polym Chem. 2005;43:5347-5393.

28. Humenik M, Huang Y, Wang Y, Sprinzl M. C-terminal incorporation of bio-orthogonal azide groups into a protein and preparation of protein-oligodeoxynucleotide conjugates by $\mathrm{Cu}$ '-catalyzed cycloaddition. ChemBioChem. 2007;8:1103-1106.

29. Zernecke A, Liehn EA, Gao JL, Kuziel WA, Murphy PM, Weber C. Deficiency in CCR5 but not CCR1 protects against neointima formation in atherosclerosisprone mice: involvement of IL-10. Blood. 2006;107:4240-4243.

30. Westrick RJ, Winn ME, Eitzman DT. Murine models of vascular thrombosis (Eitzman series). Arterioscler Thromb Vasc Biol. 2007;27:2079-2093.

31. Liu Y, Ibricevic A, Cohen JA, et al. Impact of hydrogel nanoparticle size and functionalization on in vivo behavior for lung imaging and therapeutics. Mol Pharm. 2009;6:1891-1902.

32. Drechsler M, Duchene J, Soehnlein O. Chemokines control mobilization, recruitment, and fate of monocytes in atherosclerosis. Arterioscler Thromb Vasc Biol. 2015;35:1050-1055.

33. Horuk R. Promiscuous drugs as therapeutics for chemokine receptors. Expert Rev Mol Med. 2009;11:e1.

34. Horuk R. Chemokine receptor antagonists: overcoming developmental hurdles. Nat Rev Drug Discov. 2009;8:23-33.

35. Nahrendorf M, Zhang H, Hembrador S, et al. Nanoparticle PET-CT imaging of macrophages in inflammatory atherosclerosis. Circulation. 2008;117:379-387.

36. Moore KJ, Sheedy FJ, Fisher EA. Macrophages in atherosclerosis: a dynamic balance. Nat Rev Immunol. 2013;13:709-721.

37. Tarkin JM, Joshi FR, Rudd JH. PET imaging of inflammation in atherosclerosis. Nat Rev Cardiol. 2014;11:443-457.

38. PET imaging of natriuretic peptide receptor C (NPR-C) in carotid atherosclerosis. ClinicalTrials.gov website. https://www.clinicaltrial.gov/ct2/show/NCT02417688? term $=$ woodard\&rank $=13$. Updated December 14, 2015. Accessed February $26,2016$. 